\title{
Effect of endoscopic sphincterotomy on gall bladder bile lithogenicity and motility
}

\author{
B C Sharma, D K Agarwal, S S Baijal, T S Negi, G Choudhuri, V A Saraswat
}

\begin{abstract}
Background-Endoscopic sphincterotomy has been shown to inhibit stone formation in the gall bladder of experimental animals.

Aims-To investigate the alterations in bile composition and gall bladder motility after endoscopic sphincterotomy.

Patients-A study was performed of gall bladder bile composition and gall bladder motility in patients with gallstone disease ( $(n=20$; age $40-60$ years, median age 55 years: seven men), with gall bladder calculi $(n=12)$ and with diseased gall bladder (chronic inflammation) without gall bladder calculi $(n=8)$ ), who had received endoscopic sphincterotomy for common bile duct stones. Age and sex matched disease controls comprised 20 patients with gallstone disease but without stones and an intact sphincter of Oddi (with gall bladder calculi $(n=10)$ and diseased gall bladder without gall bladder calculi $(n=10))$.
\end{abstract}

Methods-Gall bladder motility was assessed by ultrasound. Duodenal bile collected by nasoduodenal tube after stimulation of gall bladder by intravenous ceruletid infusion was analysed for cholesterol, phospholipid, and bile acid concentrations, cholesterol saturation index, and nucleation time.

Results-There was a significant reduction in mean (SEM) fasting volume (12.5 (1.7) $\mathrm{ml} v 26.4(2.5) \mathrm{ml} ; \mathrm{p}<0.001)$ and mean (SEM) residual volume $(4.34(0.9) \mathrm{ml} v$ $14.7(0.98) \mathrm{ml} ; \mathrm{p}<0.001)$, and increase in mean (SEM) ejection fraction (65.7 (4.2)\% $v 43.6(5.52) \%$; p < 0.001) and mean (SEM) rate constant of gall bladder emptying $(-0.031 / \mathrm{min} v-0.020 / \mathrm{min} ; \mathrm{p}<0.01)$ in patients who had been subjected to endoscopic sphincterotomy. Median nucleation time was significantly longer ( 17 days $v 6$ days; $p<0.006)$ in treated patients. There was a reduction in total mean (SEM) lipid concentrations $(6.73 \quad(0.32) \quad$ g/dl $v \quad 7.72$ (0.84) g/dl; p<0.05), cholesterol (5.6 (1.5) mmol/1 $v 10.3(2.23) \mathrm{mmol} / \mathrm{l} ; \mathrm{p}<0.001)$ and CSI (0.72 (0.15) $v 1.32$ (0.31); p<0.001). There was no significant change in mean (SEM) phospholipid (25.6 (3.5) $\mathrm{mmol} / \mathbf{1} v$ 23.4 (6.28) $\mathrm{mmol} / \mathrm{l})$ and bile acid (93.7 (7.31) mmol/1 $v 105.07$ (16.6) $\mathrm{mmol} / \mathrm{l})$ concentrations.

Conclusions-After endoscopic sphincterotomy there was enhanced contractility of the gall bladder, accompanied by a pro- longation of nucleation time and reduction in cholesterol saturation index.

(Gut 1998;42:288-292)

Keywords: gall bladder emptying; gall bladder contractility; nucleation time; cholesterol saturation index; gallstones; endoscopic papillotomy

Endoscopic sphincterotomy (ES) is widely used for the extraction of common bile duct (CBD) stones in both cholecystectomised patients and those with an intact gall bladder. Hutton $e^{a l^{1}}{ }^{2}$ were the first to show in a prairie dog model that ablation of the sphincter of Oddi inhibited gallstone formation despite continued supersaturation of bile. It was further shown that ablation of the sphincter both facilitates passage of glass beads of varying sizes implanted in the canine gall bladder and improves gall bladder emptying. ${ }^{5}$ Long term follow up studies of patients with gall bladders in situ after endoscopic clearance of CBD stones showed that the incidence of new stone formation was almost negligible. ${ }^{34}$ Isolated clinical observations suggested that ES may enhance gall bladder emptying in humans. ${ }^{67}$ Studies performed by $\mathrm{Li}$ et $a l^{8}$ suggested that sphincterotomy may reduce stone formation by inhibiting the effects of lithogenic bile on gall bladder muscle contractility and enhancing the ability of muscle to empty the lithogenic bile. Alterations in bile composition have been reported both in hepatic and gall bladder bile after sphincter ablation. ${ }^{9-13}$ These experimental data suggest significant alterations in gall bladder motility and bile composition after sphincter ablation ${ }^{9}$ and emphasise the need for a case control study on the effect of ES on gall bladder bile composition, nucleation time, and motility in man. We therefore studied these parameters in patients who had had ES for CBD stones while having their gall bladders in situ.

\section{Materials and methods}

We studied 20 patients with intact gall bladders, who had received ES for CBD stones and had a clear CBD as shown by endoscopic retrograde cholangiopancreaticography three months before inclusion in the study. Patients with small shrunken gall bladders (fasting volume less than $5 \mathrm{ml}$ ) were excluded. These patients were classified into two groups: $(a)$ those with gall bladder calculi (GS +$)(n=12$; age 40-60, median age 55; eight women and four men) and (b) those with diseased (chronically inflamed) gall bladders without gall bladder calculi $(\mathrm{GS}-)(\mathrm{n}=8$; age 45-55, median age 54; five women and three men). These
Accepted for publication 31 July 1997 
Table 1 Patient characteristics

\begin{tabular}{|c|c|c|c|c|}
\hline & \multicolumn{2}{|c|}{ Without sphincterotomy } & \multicolumn{2}{|c|}{ With sphincterotomy } \\
\hline & $\begin{array}{l}\text { Stones } \\
\text { present } \\
(n=10)\end{array}$ & $\begin{array}{l}\text { Stones } \\
\text { absent } \\
(n=10)\end{array}$ & $\begin{array}{l}\text { Stones } \\
\text { present } \\
(n=12)\end{array}$ & $\begin{array}{l}\text { Stones } \\
\text { absent } \\
(n=8)\end{array}$ \\
\hline Age (y) & $52(11)$ & $48(6)$ & $55(15)$ & $54(9)$ \\
\hline $\operatorname{Sex}(M: F)$ & $6: 4$ & $5: 5$ & $8: 4$ & $3: 5$ \\
\hline Serum cholesterol (mg/dl) & $176(20)$ & $180(16)$ & $180(14)$ & $190(22)$ \\
\hline Gall bladder wall thickness (mm) & $2.6(1.14)$ & $2.2(0.8)$ & $3.4(0.6)$ & $3.2(1.0)$ \\
\hline
\end{tabular}

Results are expressed as mean (SEM).

patients had a single cholesterol stone extracted from the CBD after ES. Stones collected after stool sieving were subjected to chemical analysis ${ }^{14}$ in 15 patients (eight in the GS+ group and seven in the GS- group) and had cholesterol contents greater than $50 \%$ of total dry weight. Age and sex matched (table 1) disease controls with intact papillary sphincters included: (a) 10 patients with gall bladder calculi but without CBD stones (CGS+) and (b) those who had diseased gall bladders without gall bladder calculi and CBD stones (CGS-, $n$ $=10$ ). These patients had received successful extracorporeal shock wave lithotripsy $(n=3)$ or bile acid therapy $(n=7)$ for gall bladder calculi three months before this study. Every patient was subjected to detailed clinical and biochemical examination. Oral cholecystography was carried out in both study and control patients to assess gall bladder function. Gall bladder wall thickness was measured by ultrasound in all the patients.

MEASUREMENT OF GALL BLADDER EMPTYING BY ULTRASOUND

Gall bladder volume and emptying were measured by real time ultrasonography, using a 3.5 $\mathrm{MHz}$ transducer. Patients were scanned supine in the right anterior oblique position by an experienced sonologist (SSB). The gall bladder was visualised in the longitudinal and transverse planes, and measurements of maximum length, width, and height were taken in triplicate. The volume of the gall bladder was subsequently calculated using the ellipsoid method (volume $=0.52 \times$ length $\times$ width $\times$ height). ${ }^{15}$

All patients were studied at 09.00 hours after an overnight 12 hour fast. Fasting volume of the gall bladder (FV) represented the mean of three volume measurements taken five minutes apart immediately before the start of the ceruletid infusion (Takus "R"; Farmitalia Carlo Erba Gmbh, Germany; dose 50 ng/kg per hour) for 30 minutes. During the infusion the gall bladder volume was measured every five minutes for 30 minutes. The smallest gall bladder volume observed at any time during ceruletid infusion was termed the residual volume (RV). The gall bladder ejection fraction $(\mathrm{EF} \%)$ was calculated from the equation $\mathrm{EF} \%$ $=1-(\mathrm{RV} / \mathrm{FV}) \times 100$. The rate constant of gall bladder emptying was calculated by log linear regression of gall bladder volume versus time. ${ }^{16}$

DUODENAL BILE

After a 12 hour overnight fast, patients were subjected to nasoduodenal intubation with a Bilbao-Dotter tube which was positioned using fluoroscopy. Dark thick viscous duodenal bile ${ }^{17}$ was collected after intravenous infusion of ceruletid for 30 minutes, thoroughly mixed, and divided into four aliquots. One aliquot was examined within 30 minutes under a polarising microscope, the second was stored at $37^{\circ} \mathrm{C}$ for repeat microscopic examination if required, the third was processed immediately for estimation of nucleation time, and the fourth was stored in a sealed glass vial at $-20^{\circ} \mathrm{C}$ for chemical examination.

BILE MICROSCOPY

A $2.5 \mathrm{ml}$ sample of bile was centrifuged at 2000 rpm for 10 minutes; the supernatant was discarded and the sediment examined on a glass slide under the polarising microscope. The number of cholesterol crystals under the coverslip area $(22 \times 50 \mathrm{~mm})$ was counted at $10 \times$ magnification and recorded as the number of crystals per cover slip area. If no microcrystal was seen on the first examination, the sample of bile stored at $37^{\circ} \mathrm{C}$ in the incubator was examined after 24 hours.

\section{NUCLEATION TIME OF BILE}

Nucleation time was determined by the method of Holan et a ${ }^{18}{ }^{19}$ with minor modifications. After collection, $5 \mathrm{ml}$ of bile was placed in a sterile ultracentrifuge tube and spun at $100000 \mathrm{~g}$ for two hours. The clear middle isotropic phase was transferred to a sterile plastic vial. Immediately after ultracentrifugation, this sample was examined under a polarising microscope to confirm that no crystal was present. The isotropic phase was then incubated anaerobically at $37^{\circ} \mathrm{C}$ in the dark. Thereafter a drop of bile was examined daily for the appearance of cholesterol crystals. The nucleation time was defined as the number of days from the day of collection of bile to the first day that cholesterol crystals were seen.

CHEMICAL ANALYSIS OF BILE AND CALCULATION OF CHOLESTEROL SATURATION INDEX (CSI)

Both duodenal and gall bladder bile samples were subjected to chemical analysis for cholesterol, ${ }^{14}$ phospholipids, ${ }^{20}$ and total bile acid $^{21}$. Total lipid concentration, defined as the sum of the cholesterol, phospholipids, and bile acid concentrations, was used as an indicator of bile concentration. CSI was calculated from Carey's table. ${ }^{22}$ Bile samples with a CSI of greater than one were considered supersaturated.

Data in different groups were compared using the Wilcoxon rank sum test.

\section{Results}

GALL BLADDER MOTILITY

Table 2 shows that sphincterotomised patients had significantly smaller fasting and ceruletid stimulated residual gall bladder volumes than disease controls. They also had significantly higher gall bladder ejection fractions and rate constants of gall bladder emptying compared with disease controls. Figures 1 and 2 show the effect of sphincterotomy on the time course of gall bladder emptying after ceruletid infusion; the amount emptied is expressed as a percent- 
Table 2 Gall bladder fasting volume, residual volume, and ejection fraction in patients with or without sphincterotomy

\begin{tabular}{|c|c|c|c|c|}
\hline & \multicolumn{2}{|c|}{ Without sphincterotomy } & \multicolumn{2}{|c|}{ With sphincterotomy } \\
\hline & $\begin{array}{l}\text { Stones present } \\
(n=10)\end{array}$ & $\begin{array}{l}\text { Stones absent } \\
(n=10)\end{array}$ & $\begin{array}{l}\text { Stones present } \\
(n=12)\end{array}$ & $\begin{array}{l}\text { Stones absent } \\
(n=8)\end{array}$ \\
\hline Fasting volume (ml) & $26 \quad(3)$ & $26.6(3.6)$ & $12.7(2)^{\star \star \star}$ & $12(2.4) \dagger$ \\
\hline Residual volume (ml) & $14.6(1.1)$ & $15.1(1.2)$ & $4.45(1.2)^{\star \star \star}$ & $4.2(0.9) \dagger$ \\
\hline Ejection fraction (\%) & $44 \quad(6)$ & $43 \quad(3.4)$ & $65 \quad(5)^{\star \star \star}$ & $66 \quad(4) \dagger$ \\
\hline
\end{tabular}

Results are expressed as mean (SEM).

$\star \star \star \star \mathrm{p}<0.001 ; \mathrm{tp}<0.001 v$ without sphincterotomy.

age of the control scan fasting volume. The difference in gall bladder volume emptied was significantly higher after ES for each measurement taken at five minute intervals after the start of ceruletid infusion (figs 1 and 2). The rate constant of gall bladder emptying was significantly higher in post-sphincterotomy patients compared with disease controls in both the GS+ and GS- groups $(-0.030 / \mathrm{min} v$ $-0.018 / \mathrm{min}, \mathrm{p}<0.01 ;-0.032 / \mathrm{min} v-0.022 /$ min, $\mathrm{p}<0.01$ respectively).

\section{BILE EXAMINATION}

Bile microscopy

Bile from patients in the GS+ and GS- groups did not contain cholesterol crystals. In contrast the CGS+ and CGS- groups had cholesterol crystals on bile microscopy.

Nucleation time

Nucleation time was significantly longer (17 days $v 6$ days; $\mathrm{p}<0.006$ ) in patients who had

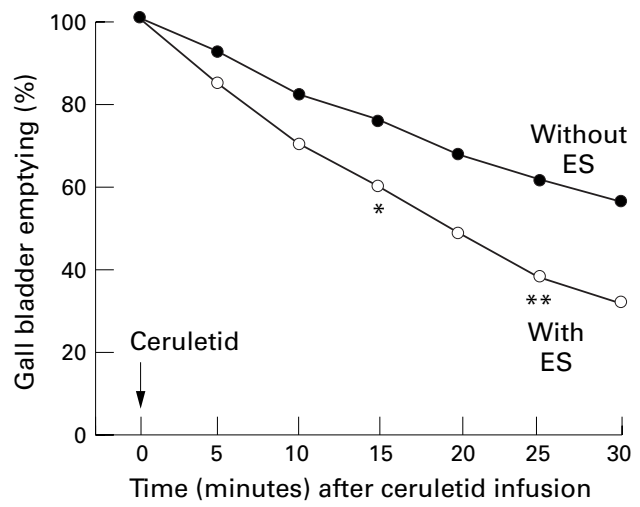

Figure 1 Time course of percentage gall bladder emptying in patients with gallstones with and without sphincterotomy. ${ }^{\star} p<0.001,{ }^{\star \star} p<0.001$.

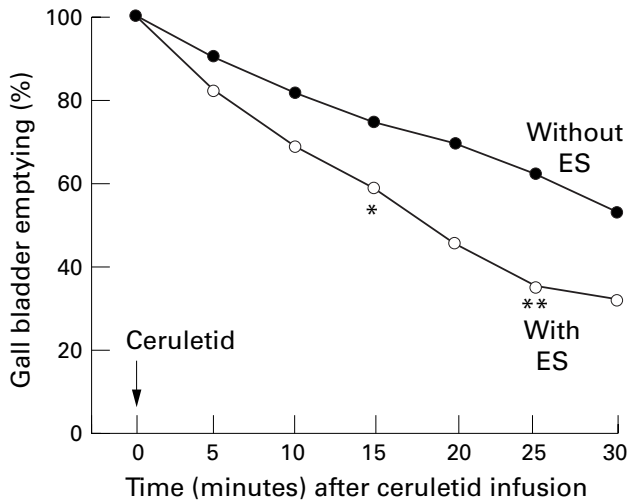

Figure 2 Time course of percentage gall bladder emptying in patients without gallstones with and without sphincterotomy. ${ }^{\star} p<0.001,{ }^{\star} p<0.001$.

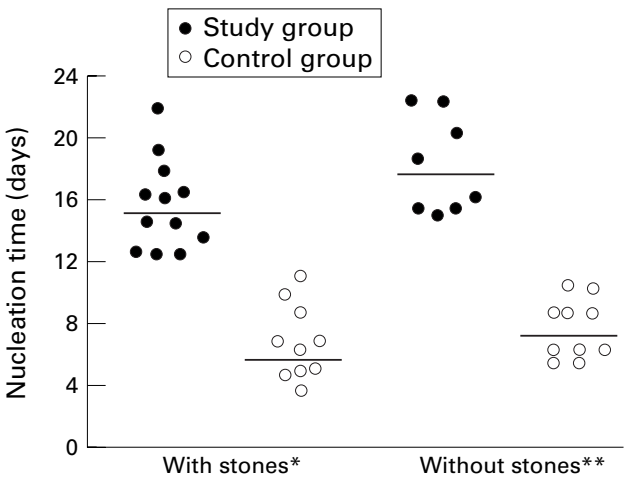

Figure 3 Nucleation time in patients with and without sphincterotomy. ${ }^{\star} p<0.006,{ }^{*} p<0.006$.

received ES. In GS+ patients, median nucleation time was 16 (range 13-21) days in post-sphincterotomy patients compared with five (3-10) days in disease controls (fig 3). In GS- patients median nucleation time was 18 (range 15-20) days in post-sphincterotomy patients compared with seven (range 5-10) days in disease controls (fig 3).

\section{Total lipid concentration and CSI}

There was significantly lower total lipid concentration $(6.73(0.32) \mathrm{g} / \mathrm{dl} v 7.72(0.84) \mathrm{g} / \mathrm{dl}$; $\mathrm{p}<0.05)$, cholesterol $(5.6(1.54) \mathrm{mmol} / \mathrm{l} v 10.3$ (2.23) $\mathrm{mmol} / \mathrm{l} ; \mathrm{p}<0.001)$, and CSI $(0.72(0.15)$ $v 1.32(0.31) ; \mathrm{p}<0.001)$ in patients who had been subjected to ES, while there were no differences in phospholipid ( 25.6 (3.5) $\mathrm{mmol} / \mathrm{l} v$ $23.4(6.28) \mathrm{mmol} / \mathrm{l}$ ) and bile acid concentration (93.7 (7.31) $\mathrm{mmol} / \mathrm{l} v 105.07$ (16.6) $\mathrm{mmol} / \mathrm{l})$. Similar results were seen on comparing the two groups separately (table 3 ).

\section{Discussion}

We have shown that patients who have had ES have greater gall bladder motility as reflected by decreased fasting and residual volumes and an increased ejection fraction and rate constant of gall bladder emptying. Also they have lower lithogenicity, cholesterol, and total lipid concentration in gall bladder bile without any reduction in bile acid and phospholipid concentrations.

Gall bladder emptying was abnormal in patients with gallstones. Impaired gall bladder emptying and reduced turn over of bile have been described previously in patients with gallstones. ${ }^{23}{ }^{24}$ Our findings of enhanced gall bladder motility after ES are consistent with results of earlier studies. ${ }^{25} 26$ Sugiyama and Atomi ${ }^{25}$ conclusively proved that ES causes significant improvement in gall bladder motility in humans and this effect lasts for more than five years. The improvement in gall bladder motility could be due to impaired gall bladder filling or enhanced emptying. Reduction in CBD pressure after sphincter destruction ${ }^{27}{ }^{28}$ facilitates gall bladder emptying. Earlier studies showed that eliminating sphincter resistance decreases gall bladder filling. ${ }^{29} 30$

Our findings of altered bile composition after ES differs from those reported in earlier studies. No significant changes in hepatic bile composition were found in two different studies 
Table 3 Gall bladder bile composition and cholesterol saturation index in patients with or without sphincterotomy

\begin{tabular}{|c|c|c|c|c|}
\hline & \multicolumn{2}{|c|}{ Without sphincterotomy } & \multicolumn{2}{|c|}{ With sphincterotomy } \\
\hline & $\begin{array}{l}\text { Stones present } \\
(n=10)\end{array}$ & $\begin{array}{l}\text { Stones absent } \\
(n=10)\end{array}$ & $\begin{array}{l}\text { Stones present } \\
(n=12)\end{array}$ & $\begin{array}{l}\text { Stones absent } \\
(n=8)\end{array}$ \\
\hline Total lipid content $(\mathrm{g} / \mathrm{dl})$ & $7.76(0.86)$ & $7.65(0.90)$ & $6.78(0.33)^{\star}$ & $6.64(0.35) \dagger$ \\
\hline Cholesterol $(\mathrm{mmol} / \mathrm{l})$ & $10.5(2.6)$ & $9.89(1.0)$ & $5.6(1.5)^{\star \star \star}$ & $5.6(1.6) \ddagger$ \\
\hline Phospholipid (mmol/l) & $24.45(6.9)$ & $23.34(5.6)$ & $25.6(3.5)$ & $25.6(3.7)$ \\
\hline Bile acid $(\mathrm{mmol} / \mathrm{l})$ & $105.7(15.3)$ & $102.8(17.5)$ & $94(7.18)$ & $94(7.87)$ \\
\hline $\begin{array}{l}\text { Cholesterol saturation } \\
\text { index }\end{array}$ & $1.32(0.32)$ & $1.33(0.32)$ & $0.72(0.15)^{\star \star \star}$ & $0.70(0.16) \ddagger$ \\
\hline
\end{tabular}

Results are expressed as mean (SEM).

${ }^{\star} \mathrm{p}<0.05,{ }^{\star \star \star} \mathrm{p}<0.001 v$ without sphincterotomy; $\mathrm{\dagger p}<0.05, \neq \mathrm{p}<0.001 v$ without sphincterotomy.

performed in dogs. ${ }^{11} 12$ Sauerbruch et $a l^{10}$ showed a reduction in total bile acid pool size after sphincterotomy in patients with intact gall bladders, but there was no difference in molar percentages of bile acids, cholesterol, and phospholipid or in mean CSI. Cohn et al ${ }^{13}$ showed reduction in lithogenicity with increase in lecithin and bile salts after sphincter of Oddi ablation. All these studies analysed hepatic bile while we studied duodenal bile. The only study analysing gall bladder bile after sphincter ablation was conducted in dogs, and showed unchanged biliary cholesterol levels but a decrease in the concentration of lecithin and bile salts, leading to an increased CSI. ${ }^{13}$ In the present study, there was a significant fall in cholesterol concentration after ES without any rise in bile acids and phospholipids; further, there was a significant reduction in total lipid concentration and CSI. The canine model used in this study may not faithfully reflect human biliary pathophysiology since the relative concentrations of cholesterol, bile salt, and phospholipid in canine bile differ from those of man. ${ }^{31}{ }^{32}$ Also Cohn et $a l^{13}$ studied healthy dogs with normal gall bladders whereas we studied humans with diseased gall bladders. The only human study analysing gall bladder bile after ES did not compare bile composition in patients with and without ES. ${ }^{33}$ Gall bladder bile composition may alter after ES either because of a change in gall bladder wall permeability as the result of regurgitation cholecystitis or rapid gall bladder bile turn over. ${ }^{121334} \mathrm{At}$ present, determination of biliary nucleation time is the best predictor for cholesterol gallstone formation. ${ }^{35}$ Our study has shown that after ES, biliary nucleation time was significantly prolonged compared with disease controls. The prolonged nucleation time in gall bladder bile in our study may be ascribed to $(a)$ decreased total biliary lipids, $(b)$ alteration in concentrations of pronucleating and antinucleating factors, and/or (c) improved gall bladder motility. It is reported that gall bladder mucosa is either impermeable to lecithin, bile salts, and cholesterol or absorbs a small fraction of biliary lipids. Permeability may be increased in the presence of bacterial contamination, which is commonly found after biliary sphincterotomy. ${ }^{13}{ }^{36}$ This may cause selective reabsorption of bile constituents by the gall bladder mucosa. ${ }^{13}$ However, there is no direct evidence for selective reabsorption of bile constituents; therefore the idea of alterations in gall bladder content being due to selective rea- bsorption of bile constituents remains speculative. Sauerbruch et $a l^{10}$ reported diminution of bile acid pool after ES in patients with an intact gall bladder. However, there were no alterations in bile acid pool in patients with cholecystectomy who already have smaller total bile acid pools. ${ }^{10}$ It is possible that duodenal and gall bladder bile have different lipid contents, although dilution cannot explain isolated low cholesterol concentration without significant difference in phospholipid and bile acid concentrations. Furthermore a dilution phenomenon is an unlikely explanation for the low cholesterol in patients who have had ES since in both groups (with ES and without ES) duodenal bile was analysed.

Experimental animal studies have shown reduced gallstone formation after sphincterotomy. ${ }^{12}$ Similar observations have been made in long term follow up studies in patients with gall bladders in situ after ES. ${ }^{45}$ Our study further supports the possibility that sphincterotomy induces changes in bile composition and gall bladder motility which would reduce the risk of recurrent cholelithiasis.

In conclusion, ES significantly prolongs nucleation time, decreases cholesterol and total lipid concentration, and does not affect phospholipid and bile acid concentrations. It also enhances gall bladder motility in patients with diseased gall bladders. These results may explain the reduced recurrence of gall bladder calculi after ES.

1 Hutton SW, Sievert CE Jr, Vennes JA, Duane WC. The effect of sphincterotomy on gallstone formation in the prairie dog. Gastroenterology 1981;81:663-7.

2 Hutton SW, Sievert CE Jr, Vennes JA, Duane WC. Inhibition of gallstone formation by sphincterotomy in the prairie dog: reversal by atropine. Gastroenterology 1982;82: 1308-13.

3 Hutton SW, Sievert CE Jr, Vennes JA, et al. Spontaneous passage of glass beads from the canine gallbladder: facilitation by sphincterotomy. Gastroenterology 1988;94:1031-5. term fate of the gallbladder after endoscopic sphincterotomy. Am F Surg 1987;154:505-9.

5 Rosseland AR, Solhaug JH. Primary endoscopic papillotomy (EPT) in patients with stones in the common bile duct and the gallbladder in situ: a 5-8 year follow-up study. World $\mathcal{F}$ Surg 1988;12:111-16.

6 Cotton PB, Vallon AG. Duodenoscopic sphincterotomy for removal of bile duct stones in patients with gallbladders. removal of bile duct stones
Surgery 1982;91:628-30

7 Cotton PB. Endoscopic management of bile duct stones (apples and oranges). Gut 1984;25:587-97.

$8 \mathrm{Li} \mathrm{YF}$, Weisbrodt NW, Moody FG. Effect of bile diversion and sphincterotomy on gallbladder muscle contractility and gallstone formation. Am F Surg 1991;162:31-5.

9 Targarona EM, Trias IPM. Effects of sphincterotomy on gallbladder physiology: a review. Endoscopy 1995;27:388-91.

10 Sauerbruch T, Stellaard T, Paumgartner G. Effect of endoscopic sphincterotomy on bile acid pool size and bile lipid composition in man. Digestion 1983;27:87-92.

11 Stellaard F, Sauerbruch T, Brunholzl C, et al. Bile acid pattern and cholesterol saturation of bile after cholecystectomy and endoscopic sphincterotomy. Digestion 1983;26: 153-8.

12 Chijiiwa K, Ogawa Y, Hirota I, Nakayama F. Biliary lipids and bile acid composition before and after endoscopic sphincterotomy. Hepatogastroenterology 1990;37:510-12.

13 Cohn MS, Schwartz SI, Faloon WW, Adams JT. Effect of sphincteroplasty on gallbladder function and bile composi tion. Ann Surg 1979;189:317-21.

14 Fromm H, Amin P, Klein H, Kupke I. Use of simple enzymatic assay for cholesterol assay. $\mathcal{F}$ Lipid Res 1980;21: 259-61.

15 Dodds WJ, Groh WJ, Darweesh RMA, et al. Sonographic measurement of gallbladder volume. AfR Am f Roentgenol 1985;145:1009-11.

16 Catnach SM, Fairclough PD, Trembath RC, et al. Effect of oral erythromycin on gallbladder motility in normal subjects and subjects with gallstones. Gastroenterology 1992;102:2071-6.

17 Juniper K, Burson EN. Biliary tract studies. II. The significance of biliary crystals. Gastroenterology 1957;32:175-211. 
18 Holan KR, Holzbach RT, Hermann RE, et al. Nucleation time: key factor in the pathogenesis of cholesterol gallstone disease Gastroenterology 1979;77:611-17.

19 Marks JW, Broomfield P, Bonorris GG, Schoenfield LJ. Factors affecting the measurement of cholesterol nucleation in human gallbladder and duodenal bile. Gastroenterology 1991;101:214-19.

20 Fiske CH, SubbaRow Y. The colorimetric determination of phosphorus. F Biol Chem 1925;66:375-8.

21 Turley SD, Dietschy JM . Enzymatic analysis of bile acids. $\mathcal{F}$ lipid Res 1978;19:924-8.

22 Carey MC. Critical table for calculating the cholesterol saturation in native bile. F lipid Res 1978;19:945-55.

23 Pomeranz IS, Shaffer EA. Abnormal gallbladder emptying in a subgroup of patients with gallstones. Gastroenterology 1985;88:787-91.

24 Jazrawi RP, Pazzi P, Petroni LM, et al. Postprandial gallbladder motor functions: refilling and turnover of bile in health der motor functions: refilling and turnover of bile in health

25 Sugiyama M, Atomi Y. Long term effects of endoscopic sphincterotomy on gallbladder motility. Gut 1996;39:856-9.

26 Agarwal DK, Sharma BC, Dhiman RK, et al. The effect of endoscopic sphincterotomy on gallbladder motility. Dig Dis Sci $1997 ; 42 \cdot 1495-500$

27 Gregg JA, Carr-Locke DL. Endoscopic pancreatic and biliary manometry in pancreatic, biliary, and papillary disease after endoscopic sphincterotomy and surgical sphincteroplasty. Gut 1984;25:1247-54.

28 Ponce J, Sala T, Pertejo V, et al. Manometric evaluation of sphincter of Oddi after endoscopic sphincterotomy and in patients with previous surgical sphincterotomy. Endoscopy 1983;15:249-51.

29 Scott RB, Eidt PB, Shaffer EA. Regulation of fasting duodenal bile acid delivery by sphincter of Oddi and gallbladder. Am f Physiol 1985;249:G22-3.

30 Desa LA, Grace PA, Henderson B, Thompson JN. Gallbladder function after endoscopic sphincterotomy. BMF 1990;300:1111-13.

31 Goldberg HI, Moss AA, Montgomery CK, et al. Contractility of inflammed gallbladder: an experimental study using the technique of cholecystokinin cholecystography. Invest Radiol 1972;7:447-53.

32 Redinger RN, Small DM. Bile composition, bile salt metabolism and gallbladder calculi. Arch Intern Med 1972; 130:618-30.

33 Meier PB, Ansol HJ, Shafer RB, Duane WC. Efficacy of chenodeoxycholic acid and ursodeoxycholic acid for lowering cholesterol saturation index of gallbladder bile in patients with a sphincterotomy. Gastroenterology 1988;95: 1595-600.

34 Large AM. Regurgitation cholecystitis and cholelithiasis. Ann Surg 1957;146:607-18.

35 Van Erpecum KJ, Van Berge Henegouwen GP, et al. Bile concentration is a key factor for nucleation of cholesterol crystal and cholesterol saturation index in gallbladder bile of gallstone patients. Hepatology 1990;11:1-6.

36 Banfield WJ. Physiology of the gallbladder. Gastroenterology 1975;69:770-6. 